\title{
Angiopoietin-like protein 4 and clinical outcomes in ischemic stroke patients
}

\section{Xiaowei Zheng ( $\square$ zxw19921212@163.com )}

Soochow University Medical College

\section{Suwen Shen}

Soochow University

\section{Aili Wang}

Soochow University

Zhengbao Zhu

Soochow University

\section{Yanbo Peng}

Soochow University

Hao Peng

Soochow University

Chongke Zhong

Soochow University

\section{Daoxia Guo}

Soochow University

\section{Tan Xu}

Soochow University

Jing Chen

Tulane University

Zhong Ju

Soochow University

\section{Deqin Geng}

Xuzhou Medical University

\section{Yonghong Zhang}

Soochow University

Jiang $\mathrm{He}$

Tulane University

\section{Original investigation}

Keywords: Angiopoietin-like protein 4, ANGPTL-4, stroke, prognosis

Posted Date: June 4th, 2020 
DOI: https://doi.org/10.21203/rs.3.rs-31690/v1

License: (c) (i) This work is licensed under a Creative Commons Attribution 4.0 International License. Read Full License

Version of Record: A version of this preprint was published at Annals of Clinical and Translational Neurology on February 22nd, 2021. See the published version at https://doi.org/10.1002/acn3.51319. 


\section{Abstract}

Background and aims Angiopoietin-like protein 4 (ANGPTL-4) had been reported to be associated with the risk of ischemic stroke, but its prognostic value remained unclear. The aim of this study was to investigate the association between plasma ANGPTL-4 concentrations and prognosis of ischemic stroke. Methods Baseline plasma ANGPTL-4 concentrations were measured in 3379 acute ischemic stroke patients. The primary outcome was a combination of death or major disability (modified Rankin Scale score, $\geq 3$ ) at 3 months after ischemic stroke, and secondary outcomes included major disability, death, stroke recurrence and vascular events. Results At 3 months after ischemic stroke, 850 (26.16\%) participants experienced major disability or died (750 major disabilities and 100 deaths). After adjusting for important covariates, odds ratios for the highest tertile of plasma ANGPTL-4 concentrations were 1.59(1.22-2.06) for primary outcome, 1.53(1.18-1.97) for major disability and 2.03(1.03-4.00) for death when compared to the lowest tertile of plasma ANGPTL-4 concentrations. For 1-SD increase of log-ANGPTL-4 concentrations (0.44 $\mathrm{ng} / \mathrm{ml})$, the adjusted odds ratios were 1.24(1.11-1.38), 1.14(1.03-1.27) and 1.72(1.32-2.23), respectively. Adding ANGPTL-4 to a model containing conventional risk factors improved risk prediction for composite outcome of death and major disability (net reclassification improvement index $=11.36 \%, p=0.014$; integrated discrimination improvement $=0.22 \%, p=0.033$ ). There were no significant associations between plasma ANGPTL-4 concentrations and risks of stroke recurrence and vascular events. Conclusion Higher plasma ANGPTL-4 concentration was associated with poor prognosis in acute ischemic stroke patients, suggesting that ANGPTL-4 might be a prognostic marker for ischemic stroke.

\section{Background}

Stroke is one of the main causes of death and long-term disability for adult worldwide, accounting for estimated 6.5 million deaths and 113 million disability-adjusted life-years in 2013(1). Several primary and secondary prevention strategies had been implemented in past decades(2-4), but the global burden and prevalence of stroke continued to increase (5). Thus, measurements of novel biomarkers may be an efficient tool for early risk stratification and improvement of therapeutic strategies.

Angiopoietin-like proteins-4(ANGPTL-4), a member of ANGPTL family, has been shown to regulate angiogenesis and to be involved in lipid, glucose, and energy metabolisms $(6,7)$. Several studies reported that increased ANGPTL-4 was associated with increased risk of hypertension(8), atherosclerosis(9), coronary artery disease(10)and stroke(11). Moreover, circulating levels of ANGPTL-4 had a positive correlation with severity of stroke and ischemic volume(12). Nevertheless, there is little about the knowledge of prognostic value of ANGPTL-4 for clinical outcomes in ischemic stroke patients. Therefore, we investigated the associations between plasma ANGPTL-4 concentrations and clinical outcomes after ischemic stroke.

\section{Study Participants And Methods}

\subsection{Study participants}


The present study was performed based on the data from the China Antihypertensive Trial in Acute Ischemic Stroke (CATIS), a multicenter, single-blind, blinded end points, randomized clinical trial conducted in 26 hospitals across China to test whether moderate lowering of blood pressure (BP) within the first 48 hours after acute ischemic stroke onset would reduce death and major disability at 14 days or hospital discharge. Details about the CATIS design, methods and main results have been previously reported(13). Briefly, a total of 4071 ischemic stroke patients aged 22 years or older confirmed by CT or MRI of the brain within 48 hours of symptom onset with an elevated systolic BP between $140 \mathrm{mmHg}$ and less than $220 \mathrm{mmHg}$ were recruited in this trial. Patients with a BP $\geq 220 / 120 \mathrm{~mm} \mathrm{Hg}$, severe heart failure, acute myocardial infarction or unstable angina, atrial fibrillation, aortic dissection, cerebrovascular stenosis, or resistant hypertension, in a deep coma, or those treated with IV thrombolytic therapy were excluded from the CATIS trial. In the present study, 692 participants were further excluded because they did not offer blood samples, or some collected samples were hemolyzed in collections of blood samples, or we failed to determine plasma ANGPTL-4 concentrations.

\subsection{Data collection}

Baseline data including demographic characteristics, clinical characteristics, medical histories, and lifestyles were collected at the time of enrollment using a standard questionnaire. Stroke severity was assessed using the National Institutes of Health Stroke Scale (NIHSS) by trained neurologists at baseline(14). Three BP measurements were obtained at baseline by trained nurses according to a common protocol adapted from procedures recommended by the American Heart Association(15). BP was measured with the participant in a supine position using a standard mercury sphygmomanometer based on arm circumference of participant. The mean of three BP measurements was used in analyses. Fasting blood samples were collected within 24 hours of hospital admission after at last 8 hour of fasting. Routine laboratory analyses (fasting blood glucose, blood lipids, blood creatinine, etc.) were performed for all enrolled patients, in each participating hospital at admission. All plasma and serum samples were frozen at $-80^{\circ} \mathrm{C}$ in the Central Laboratory of School of Public Health in Soochow University until laboratory testing.

\subsection{ANGPTL-4 detection}

Plasma ANGPTL-4 concentrations were measured centrally at Soochow University with a commercially available DuoSet ELISA kit (R\&D Systems, Minneapolis, MN). Intra-assay and interassay coefficients of variation were $3.3 \%$ and $3.9 \%$, respectively. Laboratory technicians who performed these measurements were blind to the clinical characteristics and outcomes of the study participants.

\subsection{Study outcomes}

Participants were followed up in person at 3 months after ischemic stroke by trained neurologists. The primary outcome of present study was a combination of death and major disability (modified Rankin Scale [mRS] score $\geq 3$ ). Secondary outcomes were separately those of death and major disability (modified Rankin scale score of 6 and 3-5, respectively), stroke recurrence and vascular disease events (i.e., recurrent nonfatal stroke, nonfatal myocardial infarction, hospitalized and treated angina, hospitalized and treated congestive heart failure, and hospitalized and treated peripheral arterial disease). 


\subsection{Statistical analysis}

All participants were divided into 3 groups according to tertiles of plasma ANGPTL-4 concentrations and baseline characteristics were compared across 3 groups. The generalized linear regression analysis was used to test for trend across the tertiles of ANGPTL-4 for continuous variables, and the Cochran-Armitage trend $\chi 2$ test was used for categorical variables. Multivariate logistic regression models were used to calculate odds ratios (ORs) and 95\% confidence intervals (95\% Cls) of primary and second outcomes for the highest tertile of ANGPTL-4 concentrations compared to the lowest tertile and for 1-SD increment of logtransformed ANGPTL-4 concentrations (0.44 ng/ml). Important conventional covariates like age, sex, antihypertensive treatment, time from onset to hospitalization, current smoking, current alcohol drinking, body mass index, dyslipidemia, heart disease, high-density lipoprotein cholesterol, fasting plasma glucose, history of hypertension, history of diabetes mellitus, family history of stroke, SBP at baseline, ischemic stroke subtypes and baseline NIHSS score were included in the multivariable models. Restricted cubic splines were performed to explore the shapes of the associations between plasma ANGPTL-4 concentrations and adverse clinical outcomes with 4 knots (at the 5th, 35th, 65th, and 95th percentiles). Furthermore, C statistics, net reclassification index (NRI), and integrated discrimination improvement (IDI) were used to evaluate the incremental prognostic value of plasma ANGPTL-4 concentrations beyond conventional risk factors (covariates in multivariable models) $(16,17)$.

Given that circulating ANGPTL-4 concentrations might be associated with stroke-related risk factors (i.e., obesity, metabolic syndrome, hypertension and diabetes mellitus). Thus, we performed subgroup analyses to determine the potential effect modification stratified by sex, age, baseline systolic BP, body mass index, dyslipidemia, current smoking, alcohol consumption, fasting plasma glucose and receiving immediate BP reduction in multivariate adjusted logistic regression models. Interactions between circulating ANGPTL-4 concentrations and covariates on primary outcome were tested by the likelihood ratio test of models with interaction terms. Two-tailed $p<0.05$ was considered to be statistically significant. All statistical analyses were conducted using SAS statistical software (version 9.4).

\section{Results}

\subsection{Baseline characteristics}

A total of 3379 participants were included in the present study and the baseline characteristics were well balanced between enrolled and all participants in CATIS (Supplemental Table 1), indicating that those enrolled basically represented the total participants of CATIS. Among 3379 patients, 2154 were male and the average age was $62.3 \pm 10.9$ years. The median plasma ANGPTL-4 levels were $95.3 \mathrm{ng} / \mathrm{ml}$ (interquartile range $71.4-126.5 \mathrm{ng} / \mathrm{mL}$ ). Compared to patients with low plasma ANGPTL-4 concentrations, patients with higher ANGPTL-4 concentrations tended to be older, male, have higher admission NIHSS score, systolic BP, fasting plasma glucose, total cholesterol, low density lipoprotein cholesterol and higher prevalence of history of diabetes mellitus (Table 1).

3.2 Association between plasma ANGPTL-4 concentrations and clinical outcomes of ischemic stroke 
During 3 months' follow-up, 850 (26.2\%) participants experienced major disability or died (750 major disabilities and 100 deaths). After adjusted for age, sex, admission NIHSS score and other covariates, the ORs for the highest tertile of plasma ANGPTL-4 concentrations were $1.59(95 \% \mathrm{Cl} 1.22-2.06), 1.53(95 \% \mathrm{Cl}$ 1.18-1.97) and $2.03(95 \% \mathrm{Cl} 1.03-4.00)$ for the primary outcome, major disability and death, respectively, compared with the lowest tertile. Each increased 1-SD of log-ANGPTL-4 concentration was associated with $24 \%$ (OR 1.24, 95\% Cl 1.11-1.38), 14\% (OR 1.14, 95\% Cl 1.03-1.27) and 72\% (OR 1.72, 95\% Cl 1.32-2.23) increased risk of primary outcome, major disability and death, respectively (Table 2). Multivariable-adjusted spline regression models showed a linear association between plasma ANGPTL-4 concentrations and the primary outcome $(P$ for linearity $=0.001)$ and death $(P$ for linearity $=0.001)$ (Figure 1$)$. Furthermore, Multivariable ordinal logistic regression analyses showed a significant shift in $\mathrm{mRS}$ distributions with plasma ANGPTL-4 concentrations at 3 months after ischemic stroke ( $P$ value for trend<0.001; Figure.2; Supplemental Table 2). However, we did not find any significant association between plasma ANGPTL-4 concentration and risk of stroke recurrence and vascular events.

We further examined whether adding plasma ANGPTL-4 to a model with conventional risk factors might improve the risk prediction of poor clinical outcomes after ischemic stroke. As seen in the table 4, adding ANGPTL-4 to the conventional risk factors improved continuous net reclassification index of $11.36 \%(95 \% \mathrm{Cl}$ $2.31-20.41 \% ; p=0.014)$ and integrated discrimination improvement of $0.23 \%(95 \% \mathrm{Cl} 0.11-0.44 \% ; p=0.033)$ for the composite outcome of death or major disability (Table 3).

In subgroup analyses, the significant associations of ANGPTL-4 concentrations with risk of primary outcome were observed in almost all subgroups except for the subgroup $\geq 24$ and subgroup without receiving immediate BP reduction, while no significant interactions between plasma ANGPTL-4 and any of these interested variables on primary outcome was observed (Table 4).

\section{Discussion}

Up to now, the reports on the effect of circulating ANGPTL-4 concentrations on prognosis after ischemic stroke were rarely seen, although there had been some studies suggesting that increased ANGPTL-4 concentration increase risks of hypertension ${ }^{10}$, atherosclerosis ${ }^{11}$, coronary artery disease(10), cardiovascular events(10) and stroke(11) in general population. In a case-control study, ANGPTL-4 concentrations were significantly correlated to increased NIHSS scores $(r=0.172, P=0.003)$ and large volumes of brain lesion $(r=0.124, P=0.031)$ among the cases with ischemic stroke(18), indicating that ANGPTL-4 concentrations may be associated with prognosis of ischemic stroke. We investigated the associations between plasma ANGPTL-4 concentrations and clinical outcomes after ischemic stroke in the patients from the CATIS trial with large sample size and strict data collection. In the analysis, we adjusted for almost all important established risk factors including lifestyle risk factors, medical history, clinical characteristics and admission NIHSS score. Our findings showed positive associations of increased plasma ANGPTL-4 concentrations with composite outcome of death and major disability, major disability and death at 3 months after ischemic stroke. Furthermore, subgroup analyses also showed significant associations in almost all subgroups. In addition, adding plasma ANGPTL-4 to conventional risk factors significantly improved risk-predictive ability for composite outcome of death and major disability. Our study suggested 
that increased plasma ANGPTL-4 concentrations may be an independent risk factor for poor prognosis of ischemic stroke and could improve risk prediction ability for the combined outcome of death and major disability.

Some studies had found that ANGPTL-4 loss-of-function mutations were substantially associated with lower triglyceride levels, and a lower risk of coronary artery disease and ischemic stroke(19-21). ANGPTL-4 might be involved in lipid metabolisms $(6,7)$. Accumulating evidences suggested that ANGPTL-4 regulated triglyceride in circulation by inhibiting lipoprotein lipase and modulate the uptake of free fatty acids $(22,23)$. Muendlein et al. reported that plasma ANGPTL-4 concentrations significantly predicted future cardiovascular events in patients with coronary artery disease(10). Furthermore, a case-control study found that serum ANGPTL-4 levels were significantly higher in patients with large artery atherosclerotic stroke than in healthy controls, and ANGPTL-4 concentrations were significantly correlated to increased NIHSS scores ( $r$ $=0.172, P=0.003)$ and large volumes of brain lesion $(r=0.124, P=0.031)(18)$.

Previous observational studies and randomized controlled trials had demonstrated that circulating triglycerides was one of the most important modifiable and causal risk factors for cardiovascular disease and ischemic stroke(24-26). Lipoprotein lipase is the main enzyme that hydrolyzes lipoprotein triglycerides and releases free fatty acids for tissue utilization and clearance(27). Increasing lipoprotein lipase activity could decrease serum triglyceride concentrations, whereas decreased activity of lipoprotein lipase has been shown to increase serum triglyceride concentrations and risk of cardiovascular disease $(28,29)$. Our findings had some clinical implications. It is of clinical interest to evaluate whether inhibition of ANGPTL-4 had therapeutic value in ischemic stroke patients. In fact, there had been evidence that supported ANGPTL-4 as a therapeutic target for reducing the risk of cardiovascular disease in humans(30). The mechanisms that association of increased ANGPTL-4 level with increased risk of poor prognosis after stroke are not clear. Several potential pathophysiological mechanisms might explain the association, for example, ANGPTL-4 might highly expressed under the pressure of stimuli hypoxia in endothelial cells, cardiomyocytes and ischemic brain injury $(31,32)$, and increased ANGPTL-4 level might play role in endothelial dysfunction(33), atherosclerosis(34), vascular permeability(35) and angiogenesis(34).

Our study had some limitations. First, the preset study was a post hoc analysis of CATIS and some serious patients (BP $\geq 220 / 120 \mathrm{~mm} \mathrm{Hg}$ ) or those treated with intravenous thrombolytic therapy at admission were excluded. Therefore, a selection bias may unavoidably be present. However, baseline characteristics of the participants were similar to those from the China National Stroke Registry(36), indicating that the selection bias may be minimal. Second, plasma ANGPTL-4 concentrations were tested only once for each patient at baseline, and changes over time were not considered. Third, the present study was limited to Chinese individuals, thus, the results may not be extrapolated to other race/ethnic groups. More evidences are needed to determine the validity of present findings through independent replications in more race/ethnic populations.

\section{Conclusion}


In conclusion, the present study indicated that increased plasma ANGPTL-4 concentrations at admission was associated with poor prognosis in ischemic stroke patients and adding plasma ANGPTL-4 to conventional risk factors significantly improved predictive ability for risk for composite outcome of death and major disability, indicating that ANGPTL-4 may be a potential prognostic biomarker for ischemic stroke.

\section{Abbreviations}

ANGPTL-4区Angiopoietin-like protein 4; BP: blood pressure; NIHSS: National Institutes of Health Stroke Scale; ORs: Odds ratios; NRI: Net reclassification index; IDI: Integrated discrimination improvement

\section{Declarations}

Ethics approval and consent to participate: The CATIS was d approved by the ethical committee at Soochow University in China and institutional review board at Tulane University in the USA, as well as ethical committees at the 26 participating hospitals. Written consent was obtained from all study participants or their immediate family members.

Consent for publication: Not applicable.

Availability of data and materials: Not applicable.

Competing interests: The authors declare that they have no competing interests.

Funding: This study was supported by the National Key Research and Development Program of China (grant: 2016YFC1307300), the National Natural Science Foundation of China (grant: 81673263), and a Project of the Priority Academic Program Development of Jiangsu Higher Education Institutions, China.

Author's contributions: Tan Xu, Jing Chen, YonghongZhang, and Jiang He conceived and designed the study. Tan Xu, Yanbo Peng, and Yonghong Zhang coordinated the study. Zhengbao Zhu, Chongke Zhong, Daoxia Guo, Aili Wang, Tan Xu, Hao Peng, Suwen Shen, Zhong Ju, Deqin Geng, Yonghong Zhang, and Jiang He oversaw subjects' recruitment and monitored gathering of clinical data. Yonghong

Zhang and Jiang He revised the paper.

Acknowledgments. We thank the study participants and their relatives and the clinical staff at all participating hospitals for their support and contribution to this project.

\section{References}

1. Feigin VL, Krishnamurthi RV. 13 - Global Burden of Stroke. 2016:165-206.

2. Meschia JF, Bushnell C, Boden-Albala B, Braun LT, Bravata DM, Chaturvedi S, et al. Guidelines for the Primary Prevention of Stroke: A Statement for Healthcare Professionals From the American Heart Association/American Stroke Association. Stroke.45(12):3754-832. 
3. Wang X, Qin X, Demirtas H, Li J, Mao G, Huo Y, et al. Efficacy of folic acid supplementation in stroke prevention: a meta-analysis. Lancet (London, England).369(9576):0-1882.

4. Furie KL, Kasner SE, Adams RJ. Guidelines for the prevention of stroke in patient with stroke or transient ischemic attack. Stroke. 2011;42:1-50.

5. Zhou M, Wang H, Zeng X, Yin P, Zhu J, Chen W, et al. Mortality, morbidity, and risk factors in China and its provinces, 1990-2017: a systematic analysis for the Global Burden of Disease Study 2017. Lancet (London, England). 2019;394(10204):1145-58.

6. Tai H, Tabata M, Oike Y. The Role of Angiopoietin-Like Proteins in Angiogenesis and Metabolism. Trends in Cardiovascular Medicine.18(1):6-14.

7. Oike Y, Akao M, Kubota Y, Suda T. Angiopoietin-like proteins: potential new targets for metabolic syndrome therapy.11(10):473-9.

8. Abu-Farha M, Cherian P, Qaddoumi MG, AlKhairi I, Sriraman D, Alanbaei M, et al. Increased plasma and adipose tissue levels of ANGPTL8/Betatrophin and ANGPTL4 in people with hypertension. Lipids in Health \& Disease.17(1):35.

9. Adachi H, Fujiwara Y, Kondo T, Nishikawa T, Ogawa R, Matsumura T, et al. Angptl 4 deficiency improves lipid metabolism, suppresses foam cell formation and protects against atherosclerosis. Biochem Biophys Res Commun.379(4):0-811.

10. Axel, Muendlein, Christoph, H., Saely, Andreas, et al. Angiopoietin-like protein 4 significantly predicts future cardiovascular events in coronary patients.

11. Qian, Yang, Rui-Xing, Yin, Xiao-Li, Cao, et al. ANGPTL4 variants and their haplotypes are associated with serum lipid levels, the risk of coronary artery disease and ischemic stroke and atorvastatin cholesterollowering responses.

12. Wu S, Wu B, Liu M, Chen Z, Wang W, Anderson CS, et al. Stroke in China: advances and challenges in epidemiology, prevention, and management. The Lancet Neurology. 2019;18(4):394-405.

13. He J, Zhang Y, Xu T, Zhao Q, Wang D, Chen CS, et al. Effects of immediate blood pressure reduction on death and major disability in patients with acute ischemic stroke: the CATIS randomized clinical trial. Jama. 2014;311(5):479-89.

14. Brott TG, Adams HP, Olinger CP, Marler JR, Hertzberg V. Measurements of acute cerebral infarction: A clinical examination scale. Stroke. 1989;20(7):864-70.

15. Kurtz TW, Griffin KA, Bidani AK, Davisson RL, Hall JE. Recommendations for blood pressure measurement in animals: summary of an AHA scientific statement from the Council on High Blood Pressure Research, Professional and Public Education Subcommittee. Arteriosclerosis, thrombosis, and vascular biology. 2005;25(3):478-9.

16. Delong ER, Delong DM, Clarke-Pearson DL. Comparing the Areas under Two or More Correlated Receiver Operating Characteristic Curves: A Nonparametric Approach. Biometrics. 1988;44(3):837-45.

17. Kharitonenkov A, Wroblewski VJ, Koester A, Chen YF, Clutinger CK, Tigno XT, et al. The metabolic state of diabetic monkeys is regulated by fibroblast growth factor-21. Endocrinology. 2007;148(2):774-81. 
18. He X-W, Shen Y-G, Zhu M, Hu X-F, Zheng Z, Liu P, et al. Angiopoietin-like protein 4 serum levels and gene polymorphisms are associated with large artery atherosclerotic stroke. Journal of the Neurological Sciences.362:333-8.

19. Dewey FE, Gusarova V, O'Dushlaine C, Gottesman O, Trejos J, Hunt C, et al. Inactivating Variants in ANGPTL4 and Risk of Coronary Artery Disease. The New England journal of medicine. 2016;374(12):1123-33.

20. Muendlein A, Saely CH, Leiherer A, Fraunberger P, Kinz E, Rein P, et al. Angiopoietin-like protein 4 significantly predicts future cardiovascular events in coronary patients. Atherosclerosis. 2014,237(2):632-8.

21. Yang Q, Yin RX, Cao XL, Huang F, Zhou YJ, Chen WX. ANGPTL4 variants and their haplotypes are associated with serum lipid levels, the risk of coronary artery disease and ischemic stroke and atorvastatin cholesterol-lowering responses. Nutrition \& metabolism. 2018;15:70.

22. Lafferty MJ, Bradford KC, Erie DA, Neher SB. Angiopoietin-like Protein 4 Inhibition of Lipoprotein Lipase: EVIDENCE FOR REVERSIBLE COMPLEX FORMATION. Journal of Biological Chemistry.288(40):2852434.

23. Sukonina V, Lookene A, Olivecrona T, Olivecrona G. Angiopoietin-like protein 4 converts lipoprotein lipase to inactive monomers and modulates lipase activity in adipose tissue. Proceedings of the National Academy of Sciences of the United States of America. 2006;103(46):17450-5.

24. Collaboration* TERF. Major Lipids, Apolipoproteins, and Risk of Vascular Disease. Jama the Journal of the American Medical Association.302(18):1993.

25. Willey JZ, Qiang X, Boden-Albala B, Paik MC, Elkind MSV. Lipid Profile Components and Risk of Ischemic Stroke The Northern Manhattan Study (NOMAS). Archives of Neurology. 2009;66(11):1400-6.

26. Mihaylova B, Emberson J, Blackwell L, Keech A, Baigent C. The Effects of Lowering LDL Cholesterol with Statin Therapy in People at Low Risk of Vascular Disease: Meta-Analysis of Individual Data from 27 Randomised Trials. Lancet (London, England). 2012;380(9841):581-90.

27. Wang H, Eckel RH. Lipoprotein lipase: from gene to obesity. American journal of physiology Endocrinology and metabolism. 2009;297(2):E271-88.

28. Jensen MK, Rimm EB, Rader D, Schmidt EB, S?rensen TIA, Vogel U, et al. S447X variant of the lipoprotein lipase gene, lipids, and risk of coronary heart disease in 3 prospective cohort studies.157(2):0-390.

29. Rip, J. Lipoprotein Lipase S447X: A Naturally Occurring Gain-of-Function Mutation. Arteriosclerosis, thrombosis, and vascular biology.26(6):1236-45.

30. Dewey FE, Gusarova V, O'Dushlaine C, Gottesman O, Trejos J, Hunt C, et al. Inactivating Variants in ANGPTL4 and Risk of Coronary Artery Disease. 2016;374(12):1123.

31. Galaup A, Gomez E, Souktani R, Durand M, Cazes A, Monnot C, et al. Protection Against Myocardial Infarction and No-Reflow Through Preservation of Vascular Integrity by Angiopoietin-Like 4. Circulation.125(1):140-9.

32. Wiesner G, Brown RE, Robertson GS, Imran SA, Ur E, Wilkinson M. Increased expression of the adipokine genes resistin and fasting-induced adipose factor in hypoxic/ischaemic mouse brain. 
Neuroreport.17(11):1195-8.

33. Huang RL, Teo Z, Han CC, Zhu P, Tan NS. ANGPTL4 modulates vascular junction integrity by integrin signaling and disruption of intercellular VE-cadherin and claudin-5 clusters. Blood. 2011;118(14):39904002.

34. Katano H, Yamada K. Upregulation of ANGPTL4 Messenger RNA and Protein in Severely Calcified Carotid Plaques. Journal of Stroke \& Cerebrovascular Diseases.23(5):933-47.

35. Guo L, Li SY, Ji FY, Zhao YF, Qian GS. Role of Angptl4 in vascular permeability and inflammation. Inflammation Research. 2013;63(1):13-22.

36. Luo Y, Wang X, Matsushita K, Wang C, Zhao X, Hu B, et al. Associations Between Estimated Glomerular Filtration Rate and Stroke Outcomes in Diabetic Versus Nondiabetic Patients. Stroke.45(10):2887-93.

\section{Tables}

Table 1. Baseline characteristics of the study participants according to plasma ANGPTL-4 levels

\begin{tabular}{|c|c|c|c|c|c|}
\hline \multirow[t]{2}{*}{ Characteristics } & \multirow[b]{2}{*}{ Total } & \multicolumn{3}{|c|}{ ANGPTL-4, ng/ml } & \multirow[b]{2}{*}{$P$ value } \\
\hline & & $<78.7$ & $78.7-112.9$ & $>112.9$ & \\
\hline No. of subjects & 3379 & 1073 & 1159 & 1147 & \\
\hline \multicolumn{6}{|l|}{ Demographics } \\
\hline Age, years & $62.3(10.9 \square$ & $59.6 \pm 9.7$ & $61.8 \pm 10.7$ & $65.39 \pm 11.2$ & $<0.001$ \\
\hline Male & 2154(63.8[ & $639(59.6)$ & $725(62.6)$ & $790(68.9)$ & $<0.001$ \\
\hline $\begin{array}{l}\text { Current } \text { cigarette } \\
\text { smoking }\end{array}$ & $1237(36.6)$ & $396(36.9)$ & $437(37.7)$ & $404(35.2)$ & 0.400 \\
\hline Current alcohol drinking & 1063(31.5) & $346(32.3)$ & $367(31.7)$ & $350(30.5)$ & 0.378 \\
\hline \multicolumn{6}{|l|}{ Medical history } \\
\hline History of hypertension & $2657(78.6)$ & $826(77.0)$ & $917(79.1)$ & $914(79.7)$ & 0.123 \\
\hline 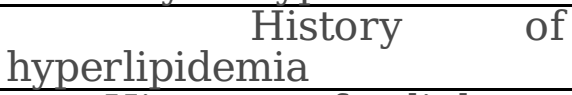 & $243(7.2)$ & $73(6.8)$ & $87(7.5)$ & $83(7.2)$ & 0.701 \\
\hline $\begin{array}{l}\text { History of diabetes } \\
\text { mellitus }\end{array}$ & $599(17.7)$ & $150(14.0)$ & $215(18.6)$ & $234(20.4)$ & $<0.001$ \\
\hline Family history of stroke & $637(18.9)$ & $199(18.6)$ & $237(20.5)$ & $201(17.5)$ & 0.517 \\
\hline \multicolumn{6}{|l|}{ Clinical features } \\
\hline NIHSS score & $4(2-8)$ & $4(2-6)$ & $4(2-7)$ & $6(3-10)$ & $<0.001$ \\
\hline $\mathrm{SBP}, \mathrm{mmHg}$ & $166(17)$ & $164(16)$ & $166(17)$ & $168(18)$ & $<0.001$ \\
\hline $\mathrm{DBP}, \mathrm{mmHg}$ & $97(11.01)$ & $97(10)$ & $97(11)$ & $97(11)$ & 0.819 \\
\hline $\mathrm{BMI}, \mathrm{kg} / \mathrm{m} 2$ & $24.9(3.1)$ & $24.8(3.10$ & $25.1(3.1)$ & $24.9(3.1)$ & 0.834 \\
\hline Blood glucose, mmol/L & $\begin{array}{ll}5.8 & (5.1- \\
7.2) & \end{array}$ & $5.5(4.9-6.7)$ & $5.8(5.0-7.3)$ & $6.0(5.3-7.7)$ & $<0.001$ \\
\hline $\mathrm{TG}, \mathrm{mmol} / \mathrm{L}$ & $1.5(1.0-2.2)$ & $\begin{array}{ll}1.5 & (1.1- \\
2.3) & \end{array}$ & $1.5(1.1-2.2$ & $\begin{array}{ll}1.4 & (1.0- \\
2.0) & \end{array}$ & 0.156 \\
\hline $\mathrm{TC}, \mathrm{mmol} / \mathrm{L}$ & $5.0(4.3-5.7)$ & $\begin{array}{l}4.9 \quad(4.2- \\
5.6)\end{array}$ & $5.0(4.3-5.7)$ & $5.1(4.3-5.9)$ & $<0.001$ \\
\hline LDL-C, mmol/L & $2.9(2.3-3.5)$ & $2.8(2.2-3.3)$ & $2.9(2.3-3.5)$ & $2.9(2.3-3.6)$ & 0.002 \\
\hline $\mathrm{HDL}-\mathrm{C}, \mathrm{mmol} / \mathrm{L}$ & $1.2(1.0-1.5)$ & $1.2(1.0-1.5)$ & $\begin{array}{ll}1.2 & (1.0- \\
1.5)\end{array}$ & $\begin{array}{ll}1.2 \\
1.5) \quad(1.0-\end{array}$ & 0.807 \\
\hline \multicolumn{6}{|l|}{ Ischemic stroke subtype } \\
\hline Thrombotic & $2642(78.2)$ & $663(77.7)$ & $644(75.5)$ & $685(76.6)$ & 0.303 \\
\hline Embolic & $164(4.9)$ & $38(4.5)$ & $44(5.1)$ & $44(5.1)$ & 0.280 \\
\hline Lacunar & $655(19.4)$ & $173(20.3)$ & $190(22.3)$ & $146(17.1)$ & 0.221 \\
\hline
\end{tabular}


SBP: systolic blood pressure; DBP: diastolic blood pressure; BMI: body mass index; TG: triglycerides; TC: total cholesterol; LDL-C: low density lipoprotein cholesterol; HDL-C: high density lipoprotein cholesterol; NIHSS, National Institute of Health Stroke Scale;

*Continuous variables are expressed as mean \pm standard deviation, or as median (interquartile range). Categorical variables are expressed as frequency (percent).

Table 2. Odds ratios and 95\% confidence interval of 3-momths outcomes according to ANGPTL-4 levels at baseline.

\begin{tabular}{|c|c|c|c|c|c|}
\hline \multirow[t]{2}{*}{ Characteristics } & \multicolumn{4}{|c|}{ ANGPTL-4, ng/ml } & \multirow{2}{*}{$\begin{array}{l}\text { Each SD increase } \\
\text { of log-ANGPTL-4 }\end{array}$} \\
\hline & $<78.7$ & $\begin{array}{l}78.7- \\
112.9\end{array}$ & $\geq 112.9$ & $P_{\text {trend }}$ & \\
\hline \multicolumn{6}{|c|}{ Primary outcome: death or major disability (mRS 3-6) } \\
\hline Case, $\mathrm{n}(\%)$ & $154(14.4)$ & $280(24.2)$ & $416(36.3)$ & & \\
\hline $\begin{array}{l}\text { Age- and sex- } \\
\text { adjusted }\end{array}$ & 1.00 (reference) & $\begin{array}{l}1.63(1.30- \\
2.05)\end{array}$ & $\begin{array}{l}2.72(2.18- \\
3.40)\end{array}$ & $<0.001$ & $1.59(1.46-1.73)$ \\
\hline adjusted Multiple- & 1.00 (reference) & $\begin{array}{l}1.44(1.11- \\
1.87)\end{array}$ & $\begin{array}{l}1.59(1.22- \\
2.06)\end{array}$ & $<0.001$ & $1.24(1.11-1.38)$ \\
\hline \multicolumn{6}{|c|}{\begin{tabular}{l|l} 
Secondary & \\
outcomes & \\
\end{tabular}} \\
\hline \multicolumn{6}{|c|}{ Major disability (mRS score 3-5) } \\
\hline Case, $\mathrm{n}(\%)$ & 141(13.1) & $\begin{array}{l}262 \\
(22.6)\end{array}$ & $347(30.3)$ & & \\
\hline $\begin{array}{l}\text { Age- and sex- } \\
\text { adjusted }\end{array}$ & 1.00 (reference) & $\begin{array}{l}1.70(1.36- \\
2.12)\end{array}$ & $\begin{array}{l}2.35(1.88- \\
2.92)\end{array}$ & $<0.001$ & $1.43(1.31-1.56)$ \\
\hline adjusted & 1.00 (reference) & $\begin{array}{l}1.47(1.13- \\
1.91)\end{array}$ & $\begin{array}{l}1.53(1.18- \\
1.97)\end{array}$ & $<0.001$ & $1.14(1.03-1.27)$ \\
\hline \multicolumn{6}{|l|}{ Death } \\
\hline Case, $\mathrm{n}(\%)$ & $13(1.2)$ & $18(1.6)$ & $69(6.0)$ & & \\
\hline $\begin{array}{l}\text { Age- and sex- } \\
\text { adjusted }\end{array}$ & 1.00 (reference) & $\begin{array}{l}1.11(0.54- \\
2.27)\end{array}$ & $\begin{array}{l}4.05(2.23- \\
7.36)\end{array}$ & $<0.001$ & $2.23(1.79-2.78)$ \\
\hline adjusted Multiple- & 1.00 (reference) & $\begin{array}{l}0.76(0.34- \\
1.69)\end{array}$ & $\begin{array}{l}2.03(1.03- \\
4.00)\end{array}$ & $<0.001$ & $1.72(1.32-2.23)$ \\
\hline \multicolumn{6}{|c|}{ Stroke recurrence } \\
\hline Case, $\mathrm{n}(\%)$ & $19(1.8)$ & $20(1.7)$ & $25(2.2)$ & & \\
\hline $\begin{array}{l}\text { Age- and sex- } \\
\text { adjusted }\end{array}$ & 1.00 (reference) & $\begin{array}{l}0.92(0.49- \\
1.74)\end{array}$ & $\begin{array}{l}1.06(0.57- \\
1.98)\end{array}$ & 0.838 & $0.95(0.74-1.23)$ \\
\hline $\begin{array}{l}\text { Multiple- } \\
\text { adjusted }\end{array}$ & 1.00 (reference) & $\begin{array}{l}0.84(0.43- \\
1.65)\end{array}$ & $\begin{array}{l}0.98(0.50- \\
1.92)\end{array}$ & 0.972 & $0.93(0.70-1.23)$ \\
\hline \multicolumn{6}{|l|}{ Vascular events } \\
\hline Case, $\mathrm{n}(\%)$ & $22(2.1)$ & $26(2.2)$ & $50(4.4)$ & & \\
\hline $\begin{array}{l}\text { Age- and sex- } \\
\text { adjusted }\end{array}$ & 1.00 (reference) & $\begin{array}{l}1.01(0.56- \\
1.80)\end{array}$ & $\begin{array}{l}1.77(1.04- \\
2.99)\end{array}$ & 0.020 & $1.22(0.99-1.51)$ \\
\hline adjusted Multiple- & 1.00 (reference) & $\begin{array}{l}0.87(0.48- \\
1.59)\end{array}$ & $\begin{array}{l}1.30(0.74- \\
2.30)\end{array}$ & 0.280 & $1.08(0.86-1.36)$ \\
\hline
\end{tabular}

Multiple-adjusted for age, sex, antihypertensive treatment, time from onset to hospitalization, current smoking, alcohol consumption, body mass index, dyslipidemia, heart disease, highdensity lipoprotein cholesterol, fasting plasma glucose, history of hypertension, history of diabetes mellitus, family history of stroke, SBP at baseline, ischemic stroke subtypes and baseline NIHSS score 
Table 3. Reclassification and discrimination statistics for 3-months clinical outcomes by plasma ANGPTL-4 among patients with acute ischemic stroke.

\begin{tabular}{|c|c|c|c|c|c|c|}
\hline \multirow[t]{2}{*}{ Characteristics } & \multicolumn{2}{|l|}{ C statistic } & \multicolumn{2}{|c|}{ NRI (continuous), \% } & \multicolumn{2}{|l|}{ IDI,\% } \\
\hline & Estimate (95\% CI) & $p$ value & $\begin{array}{l}\text { Estimate }(95 \% \\
\text { CI) }\end{array}$ & $p$ value & $\begin{array}{l}\text { Estimate } \\
(95 \% \text { CI })\end{array}$ & $p$ value \\
\hline \multicolumn{7}{|c|}{ Death or major disability (mRS score 3-6) } \\
\hline Conventional model & $0.822(0.806-0.836)$ & & Reference & & Reference & \\
\hline $\begin{array}{c}\text { Conventional } \\
\text { model+ANGPTL-4 }\end{array}$ & $0.823(0.808-0.838)$ & 0.209 & $\begin{array}{l}11.36(2.31- \\
20.41)\end{array}$ & 0.014 & $\begin{array}{l}0.23(0.11- \\
0.44)\end{array}$ & 0.033 \\
\hline \multicolumn{7}{|c|}{ Major disability (mRS score 3-5) } \\
\hline Conventional model & $0.804(0.789-0.819)$ & & Reference & & Reference & \\
\hline $\begin{array}{l}\text { Conventional } \\
\text { model+ANGPTL-4 }\end{array}$ & $0.805(0.789-0.820)$ & 0.464 & $\begin{array}{l}1.11(-8.30- \\
10.53)\end{array}$ & 0.817 & $\begin{array}{l}0.11(-0.21- \\
0.17)\end{array}$ & 0.292 \\
\hline \multicolumn{7}{|l|}{ Death } \\
\hline Conventional model & $0.819(0.804-0.833)$ & & Reference & & Reference & \\
\hline $\begin{array}{c}\text { Conventional } \\
\text { model+ANGPTL-4 }\end{array}$ & $0.830(0.816-0.845)$ & 0.204 & $\begin{array}{l}43.11(19.35- \\
66.87)\end{array}$ & $<0.001$ & $\begin{array}{l}0.85(-0.64- \\
2.33) \\
\end{array}$ & 0.26 \\
\hline
\end{tabular}

$\mathrm{NRI}=$ net reclassification improvement; IDI=integrated discrimination index.

Conventional model included age, sex, antihypertensive treatment, time from onset to hospitalization, current smoking, alcohol consumption, body mass index, , heart disease, fasting plasma glucose, history of hypertension, history of diabetes mellitus, family history of stroke, SBP at baseline, ischemic stroke subtypes and baseline NIHSS score

Table 4. Subgroup analysis of adjusted ORs (95\% CI) of primary outcome according to plasma ANGPTL-4 tertiles. 


\begin{tabular}{|c|c|c|c|c|c|c|}
\hline \multirow[t]{2}{*}{ Characteristics } & \multicolumn{4}{|c|}{ FGF-21, ng/mL } & \multirow{2}{*}{$\begin{array}{l}\text { Each SD increase of } \\
\text { log-ANGPTL-4 }\end{array}$} & \multirow[b]{2}{*}{$P$-interaction } \\
\hline & $<78.7$ & $\begin{array}{l}78.7- \\
112.9\end{array}$ & $\geq 112.9$ & $P_{\text {trend }}$ & & \\
\hline \multicolumn{7}{|l|}{ Sex } \\
\hline Male & 1.00 & $\begin{array}{l}1.48(1.05- \\
2.10)\end{array}$ & $\begin{array}{l}1.59(1.13- \\
2.23)\end{array}$ & 0.011 & $\begin{array}{l}1.20(1.04- \\
1.37)\end{array}$ & 0.413 \\
\hline Female & 1.00 & $\begin{array}{c}1.60(1.06- \\
2.42)\end{array}$ & $\begin{array}{l}1.78(1.15- \\
2.75)\end{array}$ & 0.010 & $\begin{array}{c}1.32(1.11- \\
1.57)\end{array}$ & \\
\hline \multicolumn{7}{|l|}{ Age, years } \\
\hline$<65$ & 1.00 & $\begin{array}{c}1.59(1.10- \\
2.30)\end{array}$ & $\begin{array}{l}1.70(1.20- \\
2.40)\end{array}$ & 0.014 & $\begin{array}{c}1.27(1.09- \\
1.47)\end{array}$ & 0.100 \\
\hline$\geq 65$ & 1.00 & $\begin{array}{c}1.40(0.93- \\
2.11)\end{array}$ & $\begin{array}{l}1.91(1.29- \\
2.83)\end{array}$ & $<0.001$ & $\begin{array}{c}1.29(1.11- \\
1.51)\end{array}$ & \\
\hline \multicolumn{7}{|l|}{$\begin{array}{ll}\begin{array}{l}\text { Baseline } \\
\text { mmHg }\end{array} & \\
\end{array}$} \\
\hline$<160$ & 1.00 & $\begin{array}{c}1.54(0.98- \\
2.40)\end{array}$ & $\begin{array}{c}1.87(1.19- \\
2.95)\end{array}$ & 0.008 & $\begin{array}{c}1.23(1.03- \\
1.47)\end{array}$ & 0.054 \\
\hline$\geq 160$ & 1.00 & $\begin{array}{l}1.54(1.11- \\
2.14)\end{array}$ & $\begin{array}{l}1.57(1.13- \\
2.18) \\
\end{array}$ & 0.013 & $\begin{array}{c}1.25(1.09- \\
1.43)\end{array}$ & \\
\hline \multicolumn{7}{|l|}{$\begin{array}{l}\text { Body mass } \\
\text { index, } \mathrm{kg} / \mathrm{m}^{2}\end{array}$} \\
\hline$<24$ & 1.00 & $\begin{array}{c}1.86(1.24- \\
2.80)\end{array}$ & $\begin{array}{c}2.31(1.53- \\
3.46)\end{array}$ & $<0.001$ & $\begin{array}{c}1.30(1.12- \\
1.52)\end{array}$ & 0.250 \\
\hline$\geq 24$ & 1.00 & $\begin{array}{c}1.26(0.88- \\
1.81)\end{array}$ & $\begin{array}{c}1.29(0.91- \\
1.83) \\
\end{array}$ & 0.234 & $\begin{array}{c}1.17(1.01- \\
1.37) \\
\end{array}$ & \\
\hline \multicolumn{7}{|l|}{ Dyslipidemia } \\
\hline No & 1.00 & $\begin{array}{c}1.79(1.21- \\
2.66)\end{array}$ & $\begin{array}{c}2.10(1.37- \\
2.95)\end{array}$ & 0.007 & $\begin{array}{c}1.25(1.08- \\
1.46)\end{array}$ & 0.224 \\
\hline Yes & 1.00 & $\begin{array}{c}1.17(0.80- \\
1.68)\end{array}$ & $\begin{array}{l}1.52(1.06- \\
2.20)\end{array}$ & 0.020 & $\begin{array}{c}1.23(1.05- \\
1.43)\end{array}$ & \\
\hline \multicolumn{7}{|l|}{$\begin{array}{l}\text { Cigarette } \\
\text { smoking }\end{array}$} \\
\hline No & 1.00 & $\begin{array}{c}1.40(1.01- \\
1.92)\end{array}$ & $\begin{array}{l}1.72(1.25- \\
2.38)\end{array}$ & 0.001 & $\begin{array}{c}1.27(1.12- \\
1.45)\end{array}$ & 0.088 \\
\hline Yes & 1.00 & $\begin{array}{c}1.47(0.91- \\
2.39)\end{array}$ & $\begin{array}{c}1.77(1.11- \\
2.82)\end{array}$ & 0.034 & $\begin{array}{c}1.18(0.98- \\
1.42)\end{array}$ & \\
\hline \multicolumn{7}{|l|}{$\begin{array}{l}\text { Alcohol } \\
\text { consumption }\end{array}$} \\
\hline No & 1.00 & $\begin{array}{c}1.38(1.01- \\
1.88)\end{array}$ & $\begin{array}{c}1.70(1.24- \\
2.33)\end{array}$ & 0.001 & $\begin{array}{c}1.25(1.10- \\
1.42)\end{array}$ & 0.792 \\
\hline Yes & 1.00 & $\begin{array}{c}1.45(0.86- \\
2.44) \\
\end{array}$ & $\begin{array}{c}2.04(1.23- \\
3.37)\end{array}$ & 0.019 & $\begin{array}{c}1.18(0.95- \\
1.45)\end{array}$ & \\
\hline \multicolumn{7}{|c|}{ Fasting plasma glucose, mmol/L } \\
\hline$<7$ & 1.00 & $\begin{array}{l}1.63(1.19- \\
2.23)\end{array}$ & $\begin{array}{l}1.69(1.25- \\
2.29)\end{array}$ & 0.004 & $\begin{array}{c}1.25(1.10- \\
1.41)\end{array}$ & 0.524 \\
\hline$\geq 7$ & 1.00 & $\begin{array}{l}1.24(0.75- \\
2.06) \\
\end{array}$ & $\begin{array}{c}1.63(0.99- \\
2.67) \\
\end{array}$ & 0.046 & $1.20(0.991 .47)$ & \\
\hline \multicolumn{7}{|c|}{ Receiving immediate BP reduction } \\
\hline No & 1.00 & $\begin{array}{c}1.24(0.85- \\
1.80)\end{array}$ & $\begin{array}{l}1.42(0.97- \\
2.09)\end{array}$ & 0.075 & $\begin{array}{c}1.17(1.01- \\
1.36)\end{array}$ & 0.190 \\
\hline Yes & 1.00 & $\begin{array}{l}1.84(1.26- \\
2.68)\end{array}$ & $\begin{array}{l}1.87(1.29- \\
2.72)\end{array}$ & 0.002 & $\begin{array}{c}1.31(1.12- \\
1.52)\end{array}$ & \\
\hline
\end{tabular}

In the multivariate models, confounding factors such as age, sex, antihypertensive treatment, time from onset to hospitalization, current smoking, alcohol consumption, body mass index, dyslipidemia, heart disease, high-density lipoprotein cholesterol, fasting plasma glucose, history of hypertension, history of diabetes mellitus, family history of stroke, SBP at baseline, 
ischemic stroke subtypes and baseline NIHSS score were included unless the variable was used as a subgroup variable

\section{Figures}
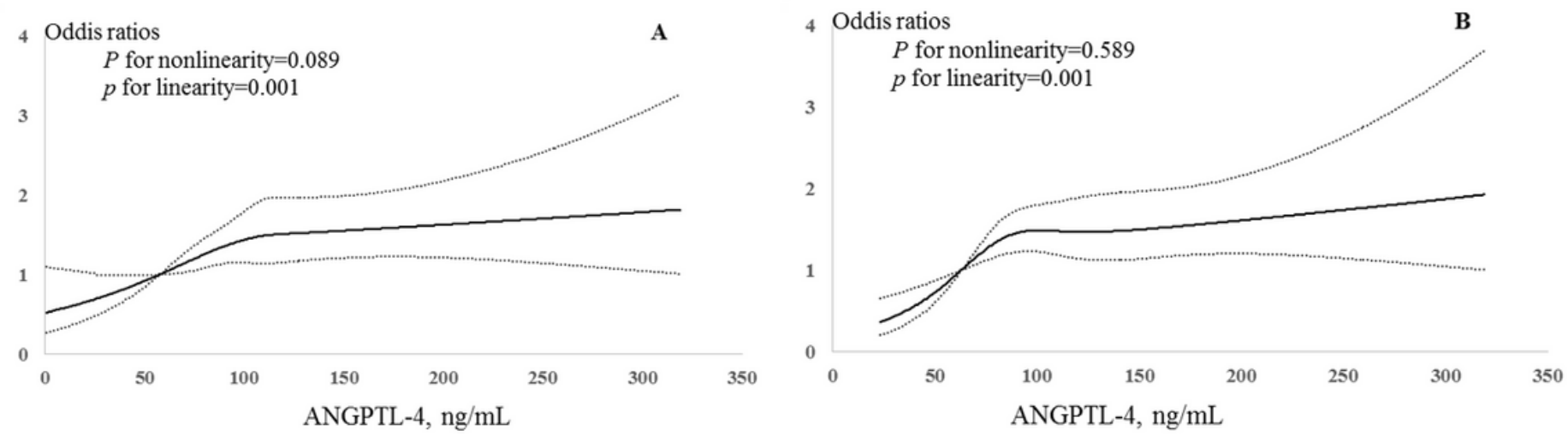

Figure 1

Relationship of plasma ANGPTL-4 with study outcomes in patients with acute ischemic stroke Odds ratios or hazard ratios and $95 \%$ confidence intervals derived from restricted cubic spline regression, with knots placed at the 5th, 35th, 65th, and 95th percentiles of the distribution of plasma ANGPTL-4. The reference point is the midpoint of the reference group from categorical analysis. Odds ratios were adjusted for covariates shown in table 2. (A) Primary outcome of death or major disability. (B) Death.

\section{Supplementary Files}

This is a list of supplementary files associated with this preprint. Click to download.

- SupplementaryMaterial.docx

- SupplementaryMaterial.docx

- SupplementaryMaterial.docx 